\title{
Encephalopathy due to sulfite oxidase deficiency
}

INSERM

\section{Source}

INSERM. (1999). Orphanet: an online rare disease and orphan drug data base.

Encephalopathy due to sulfite oxidase deficiency. ORPHA:833

Encephalopathy due to sulfite oxidase deficiency is a rare neurometabolic disorder

characterized by seizures, progressive encephalopathy and lens dislocation. 